\title{
Developmental competence of goat oocytes from follicles of different size categories following maturation, fertilization and culture in vitro
}

\author{
N. Crozet, M. Ahmed-Ali and M. P. Dubos \\ INRA, Unité de Biologie de la Fécondation, Station de Physiologie Animale, 78352 Jouy-en-Josas cédex, \\ France
}

\begin{abstract}
The aim of the present study was to investigate the effect of size of follicle from which goat oocytes originate on their subsequent ability to be fertilized and to undergo early embryonic development in vitro. Nonatretic follicles larger than $2 \mathrm{~mm}$ in diameter were dissected and distributed into three groups according to size (small: $2-3 \mathrm{~mm}$; medium: 3.1-5 mm; large: $>5 \mathrm{~mm}$ ). Cumulus-oocyte complexes were isolated from the follicles and only those with a compact multilayered cumulus were selected for in vitro maturation. After maturation, $70 \%, 83 \%$ and $97 \%$ of oocytes from small, medium and large follicles, respectively, were at metaphase II. After in vitro fertilization, no significant difference was observed in the cleavage rate $40 \mathrm{~h}$ after insemination between oocytes from small (46\%) and medium (55\%) follicles, and between oocytes from large follicles $(69 \%)$ and ovulated oocytes $(75 \%)$. After in vitro culture, significantly more embryos from small follicles arrested before or at the $8-16$ cell stage ( $84 \%$ compared with $53 \%, 45 \%$ and $39 \%$ of embryos from medium and large follicles and ovulated oocytes, respectively). The proportion of morulae and blastocysts obtained was $10 \%$ and $6 \%$ from small follicles, $35 \%$ and $12 \%$ from medium follicles, $29 \%$ and $26 \%$ from large follicles and $20 \%$ and $41 \%$ from ovulated oocytes. Oocytes from small and medium follicles yielded a significantly lower proportion of hatched blastocysts $(0 \%$ and $3 \%$, respectively) than did those from large follicles and from ovulated oocytes ( $15 \%$ and $34 \%$, respectively). These results indicate that developmental competence of goat oocytes is acquired progressively during follicular growth and that only a small proportion of oocytes, those isolated from large antral follicles, have the capacity to progress to the blastocyst stage following in vitro maturation, fertilization and culture.
\end{abstract}

\section{Introduction}

Oocyte maturation, characterized by germinal vesicle breakdown, formation of the first meiotic spindle (metaphase I), expulsion of the first polar body and arrest in metaphase of the second meiotic division (metaphase II), occurs in preovulatory follicles in response to the surge of gonadotrophins and leads to an ovulated fertilizable oocyte. Mammalian oocytes released from their follicular environment are able to undergo spontaneous nuclear maturation in vitro (Pincus and Enzmann, 1935). However, oocytes that reach metaphase II in vitro are not necessarily competent to support normal fertilization and further embryonic development (Thibault and Gérard, 1970; Moor and Trounson, 1977). Although culture conditions for in vitro oocyte maturation (IVM) in large domestic species have been improved, the developmental competence of in vitro matured oocytes, following in vitro fertilization (IVF), remains limited. In goats, the percentage of oocytes reaching metaphase II in vitro is approximately $90 \%$ and high fertilization rates have been achieved for in vitro matured oocytes (Younis et al., 1991; De Smedt et al., 1992). In addition, IVM and IVF have resuited

Received 7 November 1994 in the birth of live offspring (Crozet et al., 1993; Keskintepe et al., 1994). However, only about a third of the eggs resulting from IVM and IVF did develop to morula-blastocysts in vivo or in vitro (Crozet et al., 1993; Keskintepe et al., 1993) and, by co-culture with oviduct epithelial cells, fewer than 10\% developed into blastocysts (Keskintepe et al., 1993). From these data, it is clear that only a small proportion of goat oocytes selected for IVM can complete the full cytoplasmic maturation which confers on them the ability to support embryonic development.

Mammalian oocytes acquire meiotic competence towards the end of their growth phase. As reported in mice and pigs (Sorensen and Wassarman, 1976; Motlik et al., 1984) meiotic competence is acquired progressively during follicular growth. Goat oocytes acquired the ability to initiate resumption of meiosis in early antral follicles $0.5-0.8 \mathrm{~mm}$ in diameter and to reach metaphase I in follicles $1-1.8 \mathrm{~mm}$ in diameter (De Smedt et al., 1994). Although $86 \%$ of oocytes from follicles larger than $2 \mathrm{~mm}$ progress to metaphase II (De Smedt et al., 1992), only a small proportion of them can support embryonic development (Crozet $e$ e al., 1993), suggesting that the capacity to complete cytoplasmic maturation develops beyond the acquisition of meiotic competence. In cattle, oocytes originating from follicles larger than $6 \mathrm{~mm}$ in diameter yield a significantly higher 
percentage of blastocysts than do those from smalier follicles (Tan and Lu, 1990; McCaffrey et al., 1992; Lonergan et al., 1994). Whether oocyte quality is related to follicle size in goats has never been determined. This point deserves attention owing to the increased interest in producing goat zygotes in vitro, for gene transfer technology. Furthermore, obtaining populations of oocytes able or unable to support embryonic development, according to follicle size, may represent a useful tool with which to investigate the mechanisms controlling the acquisition of developmental competence.

The aim of the present study was to investigate the effect of follicle size on the ability of goat oocytes to be fertilized and to undergo early embryonic development in vitro. Developmental competence of the embryos resulting from IVM and IVF was evaluated by co-culture with oviduct epithelial cells. Co-culture of one-cell goat embryos produced in vivo with oviduct epithelial cells allows a high percentage of them to develop beyond the stage of cleavage arrest (8-16 cells) (Sakkas et al., 1989) and to progress to the blastocyst stage (Prichard et al., 1992). Preimplantation development in vitro, which has already been proposed as a check point for studying bovine oocyte maturation (Rose and Bavister, 1992), can therefore also be used in goats.

The present results lead to the conclusion that in goats, only oocytes from follicles about $5 \mathrm{~mm}$ in diameter can achieve full developmental competence through a standard IVM procedure. Oocytes originating from small antral follicles that complete nuclear maturation in vitro can support normal fertilization, but most of them cannot develop beyond the stage of cleavage arrest.

\section{Materials and Methods}

\section{Oocyte collection}

Goats from French Alpine and Saanen breeds were used. To obtain ovulated oocytes, does were synchronized for oestrus by treatment for 10 days with intravaginal sponges impregnated with $45 \mathrm{mg}$ fluorogestone acetate (Intervet, Angers) and by injection of $100 \mu \mathrm{g}$ of a prostaglandin analogue (Estrumate: Pitman-Moore, Meaux) $34 \mathrm{~h}$ before sponge removal. Superovulation was obtained by injecting $16 \mathrm{mg}$ pig FSH (pFSH, Rhône-Mérieux, Lyon) in decreasing doses twice a day, for 3 days. In the last four injections the FSH:LH ratio was decreased from 8 to 1.5 and 0.5 by addition of purified pig LH (Rhône-Mérieux). The goats were killed $30 \mathrm{~h}$ after i.m. injection of $100 \mu \mathrm{g}$ LHRH (UCB, Bioproducts, Nanterre) administered $4 \mathrm{I} \mathrm{h}$ after sponge removal.

Ovarian oocytes were obtained by synchronizing does for oestrus as described above. Behavioural oestrus was monitored, and follicular growth was stimulated by three injections of pFSH (3,2 and $2 \mathrm{mg})$ starting on day 14 or 15 of the oestrous cycle at 48,40 and $24 \mathrm{~h}$ before slaughter.

The genital tracts and ovaries were transported from the abattoir to the laboratory in a warm chamber $\left(30^{\circ} \mathrm{C}\right)$ within 5 min.

Ovulated oocytes were immediately recovered by retrograde flushing of the oviducts with a defined medium buffered with Hepes (DM-H, pH 7.8) (Crozet et al., 1987), at $30-35^{\circ} \mathrm{C}$.

\section{Oocyte maturation}

The ovaries were dissected and nonatretic follicles were selected and separated into three groups according to diameter: small, 2-3 mm; medium, $3.1-5 \mathrm{~mm}$; and large, $>5 \mathrm{~mm}$. The procedure for IVM was as described by De Smedt et al. (1992). Cumulus-oocyte complexes and granulosa cells were isolated from the follicles and were washed in warm TC199 medium (Gibco BRL, Eragny) buffered with $20 \mathrm{mmol}$ Hepes $\mathrm{l}^{-1}$ (pH 7.35) and containing $4 \mathrm{mmol} \mathrm{NaHCO}_{3} \mathrm{l}^{-1}$. The same medium enriched with $10 \%(\mathrm{v} / \mathrm{v})$ heat-inactived calf serum (Dutscher, Paris), $1 \mu \mathrm{g}$ oestradiol $\mathrm{ml}^{-1}$ and $10 \mu \mathrm{g} \mathrm{FSH} \mathrm{ml} \mathrm{F}^{-1}$ and $10 \mu \mathrm{g} \mathrm{LH} \mathrm{ml}^{-1}$ was used for the culture. The cumulusoocyte complexes $(5-20$ complexes) were co-cultured with granulosa cells $\left(1 \times 10^{6} \mathrm{ml}^{-1}\right)$ from follicles larger than $3 \mathrm{~mm}$ in diameter, in $2 \mathrm{ml}$ of medium, at $38.5^{\circ} \mathrm{C}$, with gentle agitation for $27 \mathrm{~h}$. Before in vitro fertilization, the oocytes were mechanically denuded from the cumulus cells in TC199 medium containing $150 \mathrm{IU}$ hyaluronidase $\mathrm{ml}^{-1}$ (Serva, Heidelberg) and were extensively washed in TC199 medium. Extrusion of the first polar body was assessed by examination under a dissecting microscope, and only matured oocytes were selected for fertilization.

\section{Sperm capacitation and fertilization}

The procedure for sperm capacitation and IVF was as reported by De Smedt et al. (1992). Fresh ejaculates obtained from a particular male of proven fertility were diluted with $8 \mathrm{ml}$ $\mathrm{DM}-\mathrm{H}$ medium. After centrifugation for $10 \mathrm{~min}$ at $200 \mathrm{~g}$, the supernatants were discarded and $50 \mu \mathrm{l}$ of the pellet was overlaid with $2 \mathrm{ml}$ of DM-H enriched with $20 \%(\mathrm{v} / \mathrm{v})$ of heat-inactived oestrous sheep serum. The spermatozoa were allowed to swim-up for $1.5 \mathrm{~h}$ at $38.5^{\circ} \mathrm{C}$, under air. The supernatants containing highly motile spermatozoa were recovered. Sperm motility was evaluated by light microscopy, and sperm concentration was measured with a Thoma cell. Spermatozoa were diluted to $1 \times 10^{7} \mathrm{ml}^{-1}$ with $\mathrm{DM}-\mathrm{H}$ containing $20 \%$ oestrous sheep serum $(\mathrm{pH} \mathrm{7.3)}$ and incubated for $5-6 \mathrm{~h}$ at $38.5^{\circ} \mathrm{C}$ in stoppered tubes. After assessment of motility, the spermatozoa were diluted for fertilization to a final concentration of $1 \times 10^{6}$ cells ml $^{-1}$ in $\mathrm{DM}-\mathrm{H}+20 \%(\mathrm{v} / \mathrm{v})$ oestrous sheep serum. The $\mathrm{pH}$ of the medium was adjusted to 7.7 by addition of $\mathrm{NaOH}$. The fertilization medium was supplemented with $7.75 \mathrm{mmol}$ calcium lactate $\mathrm{l}^{-1}(\mathrm{~L}(+)$-lactic acid, hemicalcium salt; Sigma, St Louis, MO).

Five to ten ovulated or mechanically denuded in vitro matured oocytes were added to each test tube containing $1 \mathrm{ml}$ of the sperm suspension and incubated for $17 \mathrm{~h}$ at $38.5^{\circ} \mathrm{C}$ in stoppered tubes.

\section{Source and culture of oviduct epithelial cells}

Oviduct cells were obtained from does serving as sources of ovaries. The oviducts were dissected, washed twice with PBS and flushed with TC199 Hepes medium. Oviduct mucosal tissue was extracted and transferred to a conical tube with $10 \mathrm{ml} \mathrm{TC199}$ Hepes medium. The cells were dissociated by repeated aspirations with a syringe. After decanting the supernatant, the pellet $(1 \mathrm{ml})$ was resuspended in $20 \mathrm{ml}$ TC199 
buffered with $\mathrm{NaHCO}_{3}$, containing $2 \%(\mathrm{v} / \mathrm{v})$ ultroser $\mathrm{G}$ (Gibco BRL, Eragny), $1 \%(\mathrm{v} / \mathrm{v}) 200 \mathrm{mmol}$ glutamine $\mathrm{l}^{-1}$ (Gibco BRL), $1 \mathrm{mg}, 5$ hydroxytryptamine $\mathrm{ml}^{-1}$ (Sigma), 100 iu penicillin $\mathrm{ml}^{-1}$ (Gibco BRL), $100 \mu \mathrm{g}$ streptomycine $\mathrm{ml}^{-1}$ (Gibco BRL), $250 \mu \mathrm{g}$ fungizone $\mathrm{ml}^{-1}$ (Gibco BRL) and $8 \%(\mathrm{v} / \mathrm{v})$ heat-treated fetal calf serum (Dutscher). The cells were transferred to tissue culture dishes (Nunc, Poly Labo, Paris) previously coated with $0.5 \%(\mathrm{v} / \mathrm{v})$ gelatin (swine skin type I, Sigma). Part of the cell suspension was transferred to a $25 \mathrm{~cm}^{3}$ tissue cuiture flask, as control. The cells were incubated at $39^{\circ} \mathrm{C}$ with $5 \% \mathrm{CO}_{2}$ in humidified air. Thirty hours after explantation, non-attached cells and debris were partially removed. The medium was replaced after $48 \mathrm{~h}$ and culturing lasted $96 \mathrm{~h}$. The monolayers were used for co-culture with eggs after they had reached confluence (within 5 days) and up to 2 weeks thereafter.

\section{Co-culture of embryo and oviduct cells}

Seventeen hours after oocyte insemination, the eggs were washed with fertilization medium and with $\mathrm{B}_{2}$ medium (INRA Ménézo) containing $10 \%(\mathrm{v} / \mathrm{v})$ fetal calf serum. They were transferred to the monolayers in $0.5 \mathrm{ml} \mathrm{B}$ supplemented with $10 \%(\mathrm{v} / \mathrm{v})$ fetal calf serum and were cultured for 8-9 days at $39^{\circ} \mathrm{C}$ with $5 \% \mathrm{CO}_{2}$ in humidified air.

At intervals of $24 \mathrm{~h}$, half of the medium was replaced and embryos were examined for cleavage under an inverted microscope. Gametes and embryos were manipulated in a room at $30-35^{\circ} \mathrm{C}$

\section{Cytological procedures}

After $24 \mathrm{~h}$ of co-culture, one-cell eggs were removed, fixed in acetic acid $(90 \% \mathrm{v} / \mathrm{v})-\mathrm{ethanol}(1 / 3, \mathrm{v} / \mathrm{v})$, for $24 \mathrm{~h}$ at $4^{\circ} \mathrm{C}$ and stained with lacmoid before nuclear examination by light microscopy. Those eggs containing more than two pronuclei with a sperm tail close to each male pronucleus were classified as polyspermic.

Eight days after fertilization, two blastocysts from the small, four from the medium, three from the large size follicle groups and four derived from ovulated oocytes were fixed in $0.5 \%$ $(\mathrm{v} / \mathrm{v})$ acetic acid in ethanol $(70 \% \mathrm{v} / \mathrm{v})$, for $\mathrm{Ih}$ at room temperature, rehydrated in $50 \%(\mathrm{v} / \mathrm{v})$ and $30 \%(\mathrm{v} / \mathrm{v})$ ethanol and washed in PBS for $30 \mathrm{~min}$. They were embedded in gelatin $10 \%(\mathrm{v} / \mathrm{v})$ in PBS and cooled in isopentane $\left(-130^{\circ} \mathrm{C}\right)$. Cryostat sections $(10 \mu \mathrm{m})$ were exposed for $15 \mathrm{~s}$ to Hoechst dye 33258 (Sigma) for chromatin staining, rinsed in PBS and mounted in Citifluor (City University, London) before examination and counting the number of cells under an epifluorescence microscope.

\section{Statistical analyses}

Statistical analyses were conducted by means of Chi-squared analyses or the Fisher exact test, as appropriate. Each group was compared with its neighbour and to the group of ovulated oocytes.

\section{Results}

A total of 543 healthy antral follicles were dissected from 23 does, of which 173 were classified as small follicles, $2-3 \mathrm{~mm}$ in
Table 1. Recovery and selection of cumulus-oocyte complexes from follicles of different size

\begin{tabular}{lcc}
\hline Source of oocytes & $\begin{array}{c}\text { Number of } \\
\text { isolated COCs }\end{array}$ & $\begin{array}{c}\text { Number of intact } \\
\text { COCs selected for } \\
\text { IVM (\%) }\end{array}$ \\
\hline Small follicles $(2-3 \mathrm{~mm})$ & 173 & $107(62)^{\mathrm{a}}$ \\
Medium follicles $(3.1-5 \mathrm{~mm})$ & 157 & $132(84)^{\mathrm{b}}$ \\
Large follicles $(>5 \mathrm{~mm})$ & 213 & $185(87)^{\mathrm{b}}$ \\
\hline
\end{tabular}

Data from 23 goats in nine experiments. COC: cumulus-oocyte complex.

${ }^{a b}$ Values in the same column with different superscripts are significantly different $(P<0.001)$.

Table 2. In vitro maturation of goat oocytes from follicles of different size

\begin{tabular}{lcc} 
Source of oocytes & $\begin{array}{c}\text { Number of } \\
\text { oocytes cultured }\end{array}$ & $\begin{array}{c}\text { Number of oocytes } \\
\text { in metaphase II (\%) }\end{array}$ \\
\hline Small follicles $(2-3 \mathrm{~mm})$ & 105 & $74(70)^{\mathrm{a}}$ \\
Medium follicles $(3.1-5 \mathrm{~mm})$ & 127 & $105(83)^{\mathrm{b}}$ \\
Large follicles $(>5 \mathrm{~mm})$ & 159 & $154(97)^{\mathrm{c}}$
\end{tabular}

Results are from nine experiments.

Values in the same column with different superscripts are significantly different ${ }^{\mathrm{ab}}(P<0.05),{ }^{\mathrm{bc}}(P<0.01)$.

diameter; 157 as medium follicles, $3.1-5 \mathrm{~mm}$ in diameter; and 213 as large follicles, $>5 \mathrm{~mm}$ in diameter. Only cumulusoocyte complexes with a compact, multilayered cumulus were selected for IVM. The proportion of cumulus-oocyte complexes selected in each category is shown in Table 1. Significantly more high-quality cumulus-oocyte complexes were obtained from the medium and large follicle size groups than from the small size group ( $84 \%$ and $87 \%$ compared with $62 \%$; $P<0.001$ ).

The number of oocytes reaching metaphase II within $27 \mathrm{~h}$ of culture increased progressively with follicular size: $70 \%, 83 \%$ and $97 \%$ of oocytes from the small, medium and large groups completed nuclear maturation, respectively (Table 2). Significant differences were found between the small and medium groups $(P<0.05)$ and between the medium and large groups $(P<0.01)$.

Only mature oocytes that exhibited a polar body were subsequently used for IVF. In each experiment, in addition to oocytes from the different groups, ovulated oocytes were used as controls. Semen from a single male was used throughout these experiments to avoid differences in fertilizing ability and embryonic development capacity among males. The cleavage rate $40 \mathrm{~h}$ after insemination increased progressively from $46 \%$ in the small group to $69 \%$ in the large group and was $75 \%$ in ovulated oocytes (Table 3). No significant difference was observed in the cleavage rate between the small and medium groups and between the large and ovulated oocyte groups. However, oocytes from the large group yielded a significantly higher proportion of cleaving embryos than did oocytes from the medium group $(P<0.05)$. Uncleaved eggs were either 
Table 3. In vitro fertilization of goat oocytes from follicles of different size

\begin{tabular}{lccr}
\hline Source of oocytes & $\begin{array}{c}\text { Number of } \\
\text { inseminated oocytes }\end{array}$ & $\begin{array}{c}\text { Number of cleaved eggs } \\
40 \mathrm{~h} \text { after insemination (\%) }\end{array}$ & $\begin{array}{c}\text { Number of } \\
\text { polyspermic eggs (\%) }\end{array}$ \\
\hline Small follicles (2-3 mm) & 68 & $31(46)^{\mathrm{a}}$ & $9(13)$ \\
Medium follicles $(3.1-5 \mathrm{~mm})$ & 93 & $51(55)^{\mathrm{a}}$ & $10(11)$ \\
Large follicles (> $5 \mathrm{~mm})$ & 143 & $98(69)^{\mathrm{b}}$ & $12(8)$ \\
Ovulated & 128 & $96(75)^{\mathrm{b}}$ & $12(9)$ \\
\hline
\end{tabular}

Results are from nine experiments.

${ }^{a b} V$ alues in the same column with different superscripts are significantly different $(P<0.05)$.

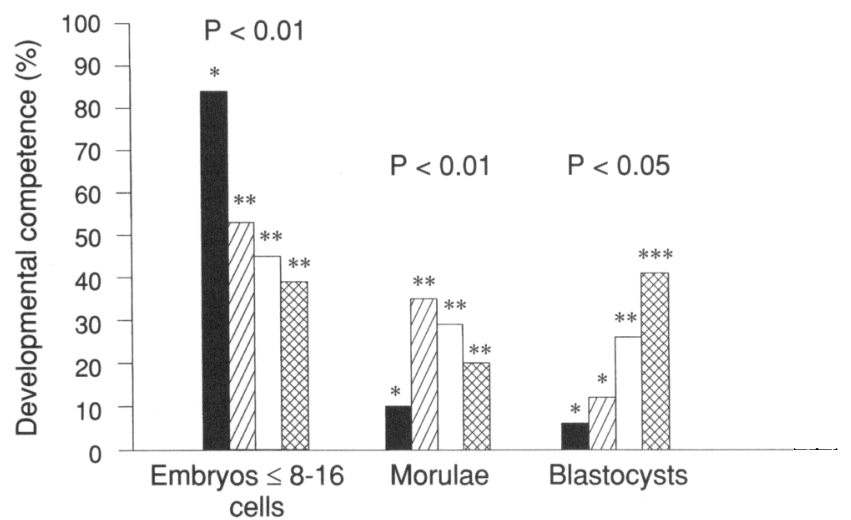

Fig. 1. Developmental competence of goat oocytes from follicles of different size cultivated for 8 days after fertilization in vitro. ( $\square$ ): small

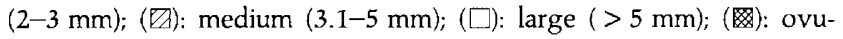
lated oocytes. Results are from nine experiments. Values in the same group with different numbers of asterisks are significantly different (embryo $\leq 8-16$ cells and morulae $P<0.01$; blastocysts $P<0.05$ ).

unfertilized or penetrated by more than one spermatozoon. Polyspermy, primarily dispermy, which affected $13 \%, 11 \%, 8 \%$ and $9 \%$ of the inseminated oocytes from the small, medium, large and ovulated oocyte groups, respectively, was the only abnormality detected.

Developmental competence was evaluated by examining cleaved embryos from the different groups each day during the culture period. Significantly more embryos from the small group arrested before or at the 8-to-16 cell stage $(84 \%$ compared with $53 \%, 45 \%$ and $39 \%$ in the medium, large and ovulated oocyte groups, respectively $(P<0.01)$ (Fig. 1 ).

The proportions of morulae and blastocysts found 8 days after fertilization were $10 \%$ and $6 \%$, respectively, in the small group, $35 \%$ and $12 \%$ in the medium group, $29 \%$ and $26 \%$ in the large group and $20 \%$ and $41 \%$ in the ovulated oocyte group (Fig. 1). Oocytes from medium-sized antral follicles yielded significantly more morulae than did those from small antral follicles $(P<0.01)$, but they yieided significantly fewer blastocysts than did oocytes derived from large follicles $(P<0.05)$. However, it should be noted that embryos developing to the morula stage 8 days after fertilization were probably not viable. Significantly more ovulated oocytes developed to the blastocyst stage (41\% compared with $26 \%$ in the large group) $(P<0.05)$ (Fig. 1). The proportions of hatched blastocysts in the large and ovulated oocyte groups, $15 \%$ and $34 \%$, respec-

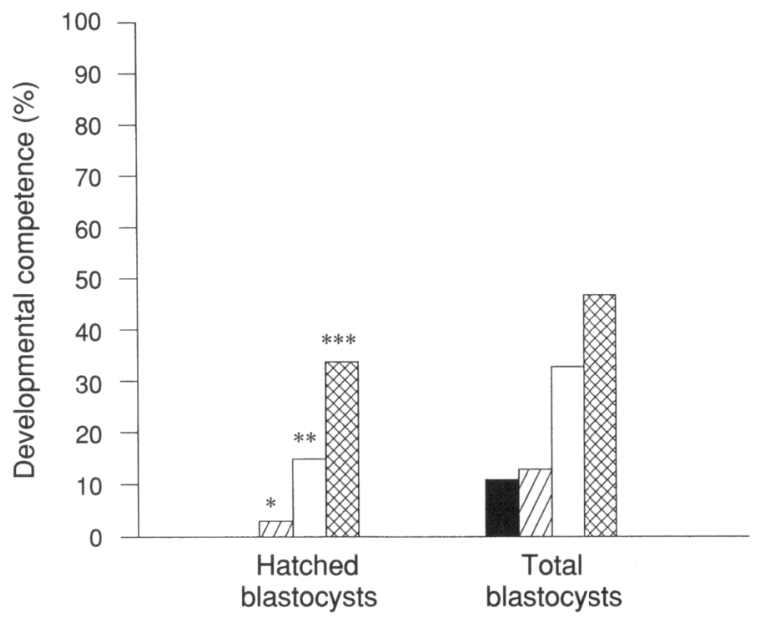

Fig. 2. Developmental competence of oocytes from follicles of different size cultivated for 9 days after fertilization in vitro. ( $\mathbf{\square})$ : small $(2-3 \mathrm{~mm})$; $(\square)$ : medium (3.1-5 mm); ( $\square)$ : large (>5 mm); ( lated oocytes. Results are from six experiments. Values with different numbers of asterisks are significantly different: $* * *(P<0.05)$; $* * * * *(P<0.01)$

tively, 9 days after fertilization (Fig. 2), were approximately double those found on the previous day (data not shown). Oocytes derived from large follicles yielded significantly fewer hatched blastocysts than did ovulated oocytes $(P<0.01)$ (Fig. 2). In the small and medium groups, the percentage of hatched blastocysts was very low (zero and 3\%, respectively) (Fig. 2).

Six blastocysts of the seven obtained 8 days after fertilization from the small and medium groups were examined on frozen sections, after Hoechst dye staining. They contained fewer than 50 cells, and their inner cell mass was undetectable. In contrast, blastocysts from the large and ovulated oocyte groups at this time contained over 150 cells and their inner cell mass had over 20 cells.

\section{Discussion}

Results from the present study demonstrate a clear relationship between follicle size and the in vitro developmental competence of goat oocytes matured and fertilized in vitro by the procedure reported by De Smedt et al. (1992). Whereas oocytes originating from follicles $>5 \mathrm{~mm}$ in diameter yielded a proportion of blastocysts comparable to that of ovulated oocytes, those from 
small antral follicles lacked developmental competence. In cattle, the size of follicles from which oocytes are derived affects their developmental competence (Tan and Lu, 1990; Galli and Moor, 1991; Pavlok et al. 1992; Lonergan et al., 1994) but, to our knowledge, this report is the first to document a relationship between follicle size and oocyte quality in goats. In both ruminant species, oocytes from large follicles yielded a significantly higher percentage of blastocysts than did oocytes from small antral follicles. Bovine oocytes from medium antral follicles yielded fewer blastocysts than did oocytes from large follicles. However, identical hatching rates suggest that embryos derived from medium and large follicles are of equal biological quality (Tan and Lu, 1990; Pavlok et al., 1992; Lonergan et al., 1994). In contrast, goat oocytes derived from medium antral follicles exhibited poor developmental capacity, as shown by the low rates of blastocyst formation and hatching. The small number of cells in the whole blastocysts and in the inner cell masses further suggested that embryos from this group were unable to support subsequent development.

Fertilization abnormalities, such as failure of sperm decondensation and male pronuclear formation, that are likely to be due to insufficiences in cytoplasmic maturation, were not observed in fertilized goat oocytes from follicles $\geq 2 \mathrm{~mm}$ in diameter. Polyspermy, which affected approximately $10 \%$ of both in vitro and in vivo matured oocytes, most likely resulted from IVF conditions. These data indicated that a large proportion of goat oocytes from follicles $\geq 2 \mathrm{~mm}$ in diameter were competent to support normal fertilization under the present IVM/IVF conditions. In contrast, bovine oocytes from follicles $\geq 2 \mathrm{~mm}$ in diameter display a high incidence of fertilization abnormalities after IVM/IVF (Pavlok et al., 1992).

De Smedt et al. (1994) reported that the acquisition of meiotic competence by goat oocytes occurs progressively during follicular growth. The oocytes become capable of resuming meiosis in antral follicles $0.5-0.8 \mathrm{~mm}$ in diameter. They can reach metaphase I in follicles $1.0-1.8 \mathrm{~mm}$ in diameter and progress to metaphase II in larger follicles. Data from the present study further indicated that the proportion of oocytes completing nuclear maturation significantly increased as follicles enlarged from 2 to $5 \mathrm{~mm}$. Full maturation involves both nuclear and cytoplasmic events that confer on the oocyte the capacity for supporting normal fertilization and early embryonic development (Thibault and Gérard, 1970; Moor and Trounson, 1977). The results reported here clearly indicate that competence to undergo cytoplasmic maturation was also acquired progressively by the oocyte, during follicular growth. In agreement with the present findings, Eppig et al. (1994) reported that mouse oocytes acquire their developmental competence in a stepwise manner. Approximately half of goat oocytes from follicles $2-3 \mathrm{~mm}$ in diameter were competent to support normal fertilization, but most of them failed to develop beyond the 8-16 cell stage. The lack of some type of mRNA could be one reason for cleavage arrest in embryos from this group. De Smedt et al. (1994) reported that goat oocytes from follicles $2 \mathrm{~mm}$ in diameter are still actively engaged in RNA synthesis, and enter a period of low transcriptional activity in $3 \mathrm{~mm}$ follicles. Half of the oocytes from follicles $3-5 \mathrm{~mm}$ in diameter could develop in vitro beyond the 8-16 cell stage, but most of them arrested at the morula stage, before blastomere compaction. One possible explanation could be that specific maternal mRNAs, critical for compaction and for blastocyst differentiation, accumulate in the oocyte during the final phase of follicular growth. Our findings indicated that oocytes from large follicles were superior to oocytes from small and medium antral follicles in terms of developmental capacity to the blastocyst stage. This finding suggests that in follicles about $5 \mathrm{~mm}$ in diameter goat oocytes have synthesized the maternal factors required to support normal maturation, fertilization and early embryonic development. Further studies are necessary to provide information on these maternal factors responsible for the acquisition of developmental competence. The availability of oocytes from follicles of different size progressing to different stages of early embryonic development represents an important tool for such studies.

The present findings also emphasize the necessity, for studies or applications that require full developmental potential, to select oocytes according to follicle size. Keskintepe $e t$ al. (1994) reported that $40 \%$ of goat embryos resulting from IVM and IVF progress in vitro to the morula stage but fail to develop into blastocysts. In another series of experiments, using co-culture with oviduct epithelial cells, only a few blastocysts were obtained (Keskintepe et al., 1993). The authors concluded that methods for sustaining in vitro development up to the blastocyst stage of in vitro matured and fertilized goat oocytes have not yet been developed (Keskintepe et al., 1994). However, oocytes from follicles $2-5 \mathrm{~mm}$ in diameter were used in these experiments, and as shown in the present study, most oocytes from medium antral follicles failed to progress beyond the morula stage. By selecting oocytes from large follicles, 30\% of blastocysts were obtained under the IVM/IVF and embryo culture conditions used in the present study. This blastocyst rate fell within the range of values reported for bovine oocytes using standard IVM/IVF and embryo culture procedures (Tan and Lu, 1990; Pavlok et al., 1992; Lonergan et al., 1994). Administration of pFSH beginning 3 days before slaughter has been shown to increase the number of large follicles in the ovaries of heifers and hence to increase the number of oocytes competent to support embryonic development following IVM/ IVF and embryo culture (Lonergan ef al., 1994). We can speculate that FSH-priming, as used in the present experiments, may also increase the number of large follicles in goat ovaries. It would be interesting for further applications to compare the embryo yield per ovary of goats with or without pFSH treatment.

Although the developmental competence of goat oocytes from follicles $>5 \mathrm{~mm}$ in diameter and of those of ovulated oocytes were comparable, ovulated oocytes were superior especially in terms of blastocyst hatching. This may be due to the conditions for oocyte maturation that are critical for subsequent embryonic development, conditions in vivo offering a better environment than conditions in vitro. It is evident, both from our data and from those of others, that preimplantation development is a valuable criterion for evaluating the conditions for oocyte maturation in vitro. The introduction of ovulated oocytes, as a control in the experiments, is also important for interpreting the results obtained.

In the present study, the viability of IVM/IVF embryos was not confirmed by transfer to recipient goats, the only conclusive test of developmental competence. However, previous 
experiments indicated that in vitro matured and fertilized oocytes produced through the IVM/IVF procedure described are viable and can produce term offspring (Crozet et al., 1993).

In conclusion, the present results indicate that the competence to undergo cytoplasmic maturation is acquired progressively by the goat oocyte during final follicular growth. The capacity to be normally fertilized and to support early cleavage is acquired concomitantly to meiotic competence. Further differentiation of the oocytes enables them to develop at first, through the period of cleavage arrest and thereafter, to progress to the blastocyst stage.

It is important to stress, for further applications, that only a small proportion of goat oocytes isolated from antral follicles have the capacity to support embryonic development in vitro.

Purified FSH was a gift provided by the Institut Rhône-Mérieux, Lyon, France. The authors thank A. Solari for statistical analysis, C. Sévellec for assistance in IVM and Y. Lavergne for technical assistance.

\section{References}

Crozet N, Huneau D, De Smedt V, Théron MC, Szöllösi D, Torrès S and Sévellec C (1987) In vitro fertilization with normal development in the sheep Gamete Research 16 159-170

Crozet N, De Smedt V, Ahmed-Ali M and Sévellec C (1993) Normal development following in vitro oocyte maturation and fertilization in the goat Theriogenology 39206 (Abstract)

De Smedt V, Crozet N, Ahmed-Ali M, Martino A and Cognié Y (1992) In vitro maturation and fertilization of goat oocytes Theriogenology 37 1049-1060

De Smedt V, Crozet N and Gall L (1994) Morphological and functional changes accompanying the acquisition of meiotic competence in ovarian goat oocyte Journal of Experimental Zoology 269 128-139

Eppig JJ, Schultz RM, O'Brien M and Chesnel P (1994) Relationship between the developmental programs controlling nuclear and cytoplasmic maturation of mouse oocytes Developmental Biology 164 1-9

Galli C and Moor RM (1991) Development of immature bovine oocytes into viable embryos in vitro Bulletin de l'Association des Anatomistes 75 67-71
Keskintepe L, Darwish GM, Paramio MT and Brackett BG (1993) Caprine oocyte fertilization and development in vitro Biology of Reproduction $\mathbf{4 8}$ (Supplement 1), 171 (Abstract)

Keskintepe L, Darwish GM, Younis AI and Brackett BG (1994) In vitro development of morulae from immature caprine oocytes Zygote 2 97-102

Lonergan P, Monaghan P, Rizos D, Boland MP and Gordon L (1994) Effect of follicle size on bovine oocyte quality and developmental competence following maturation, fertilization, and culture in vitro Molecular Reproduction and Development $3748-53$

McCaffrey C, Lu KH and Sreenan JM (1992) Factors involved in the in vitro development of IVF cattle ova Proceedings of the Irish Grassland and Animal Production Association, 18th Annual Research Meeting, Dublin, pp 33-34

Moor RM and Trounson AO (1977) Hormonal and follicular factors affecting maturation of sheep oocytes in vitro and their subsequent developmental capacity Journal of Reproduction and Fertility 49 101-109

Motlik J, Crozet N and Fulka J (1984) Meiotic competence in vitro of pig oocytes isolated from early antral follicles Journal of Reproduction and Fertility $72323-328$

Pavlok A, Lucas-Hahn A and Nieman H (1992) Fertilization and developmental competence of bovine oocytes derived from different categories of antral follicles Molecular Reproduction and Development 31 63-67

Pincus G and Enzmann EV (1935) The comparative behavior of mammalian eggs in vivo and in vitro. I. The activation of ovarian eggs Journal of Experimental Medicine 62 665-675

Prichard JF, Thibodeaux JK, Pool SH, Blakewood EG, Ménézo Y and Godke RA (1992) In vitro co-culture of early stage caprine embryos with oviduct and uterine epithelial cells Human Reproduction 7 553-557

Rose TA and Bavister BD (1992) Effect of oocyte maturation medium on in vitro development of in vitro fertilized bovine embryos Molecular Reproduction and Development 31 72-77

Sakkas D, Batt PA and Cameron AWN (1989) Development of preimplantation goat (Capra hircus) embryos in vivo and in vitro Journal of Reproduction and Fertility 87 359-365

Sorensen RA and Wassarman PM (1976) Relationship between growth and meiotic maturation of the mouse oocyte Developmental Biology 50 531-536

Tan SJ and Lu KH (1990) Effects of different oestrous cycle stages of ovaries and sizes of follicles on generation of IVF early embryos Theriogenology 33 335

Thibault, C and Gérard M (1970) Facteur cytoplasmique nécessaire à la formation du pronucleus mâle dans l'ovocyte de lapine Comptes Rendus de l'Académie des Sciences Paris D 270 2025-2026

Younis AI, Zuelke KA, Harper KM Oliveira AL and Brackett BG (1991) In vitro fertilization of goat oocytes Biology of Reproduction 44 1177-1182 